\title{
Accuracy of Medical Oxygen Flowmeters: A Multicentric Field Study
}

\author{
Frédéric Duprez ${ }^{1,2,3^{*}}$, Maria Barile², Thierry Bonus ${ }^{2}$, Grégory Cuvelier ${ }^{3}$, Sandra Ollieuz ${ }^{2}$, \\ Shahram Mashayekhi², Alexandre Legrand ${ }^{*}$ \\ ${ }^{1}$ Department of Physiology and Pharmacology, University of Mons, Mons, Belgium \\ ${ }^{2}$ Intensive Care Unit, Centre Hospitalier Epicura, Hornu, Belgium \\ ${ }^{3}$ Laboratory of Motion, Haute Ecole Condorcet, Tournai, Belgium \\ Email: frederic.duprez@condorcet.be, ${ }^{*}$ alexandre.legrand@umons.ac.be
}

Received 27 May 2014; revised 17 July 2014; accepted 5 August 2014

Copyright (C) 2014 by authors and Scientific Research Publishing Inc.

This work is licensed under the Creative Commons Attribution International License (CC BY).

http://creativecommons.org/licenses/by/4.0/

(c) (†) Open Access

\begin{abstract}
The accuracy of 476 oxygen flowmeters was investigated using a thermal mass flowmeter in eight hospitals in France and Belgium. Different oxygen flow rates ( 2 to $15 \mathrm{l} / \mathrm{min}$ ) were evaluated at the patient's bed. When the sample was considered as a whole, the accuracy of delivered flow was acceptable but precision was poor. The variability of the delivered flow between devices was greater when a low flow rate was required. Compensated-pressure oxygen flowmeters for these low rates were more accurate than their non-compensated counterparts. This study emphasizes the need to individually adapt the oxygen flow rate each time a patient has to move from one flowmeter to another.
\end{abstract}

\section{Keywords}

Medical Device Accuracy, Oxygen Therapy, Flowmeter

\section{Introduction}

Oxygen is commonly delivered in both chronic and acute patient care. In 2008, 18\% of hospitalized patients in Great Britain received oxygen on a daily basis [1]. The appropriate oxygen flow rate varies widely from one situation to the other. Patients with severely altered blood gas exchange may need a high inspiratory concentration of oxygen. In these situations, a Non Rebreather Mask (or reservoir mask) is typically used and requires oxygen flow rates as high as 12 to $15 \mathrm{l} / \mathrm{min}$ [2]. For other patients, an oxygen flow rate between 2 to $10 \mathrm{l} / \mathrm{min}$ by nasal prongs or simple mask is generally sufficient to ensure appropriate oxygenation [2].

Oxygen therapy can however be deleterious. Its concomitant use with bleomycin [3] or paraquat (1,1 dimethyl

${ }^{*}$ Corresponding authors.

How to cite this paper: Duprez, F., Barile, M., Bonus, T., Cuvelier, G., Ollieuz, S., Mashayekhi, S. and Legrand, A. (2014) Accuracy of Medical Oxygen Flowmeters: A Multicentric Field Study. Health, 6, 1978-1983.

http://dx.doi.org/10.4236/health.2014.615232 
4,4' bipyridylium) may cause irreversible pulmonary fibrosis leading to death [4]. High inspiratory oxygen fractions are associated with retrolental fibroplasia in premature infants [5] or atelectasis by oxygen denitrogenation [6]. Recently, some authors have also demonstrated that hyperoxia could induce potentially harmful cerebral and myocardial vasoconstriction in ischemic diseases [7].

A reasonable target for oxygen therapy is therefore to reach a saturation of hemoglobin $\left(\mathrm{SpO}_{2}\right)$ between 94 and 98\% [2]. For patients with chronic obstructive pulmonary disease or patients with atelectasis by oxygen denitrogenation, the risk of respiratory acidosis is increased when oxygen is generously delivered. To avoid this acidosis, $\mathrm{SpO}_{2}$ must be kept between $88 \%$ and $92 \%$. However, when an arterial blood gas analyzer is available, this range can be extended to $94 \%$ - 98\% and the oxygen flow rate is then adapted according to the evolution of arterial pressure of $\mathrm{CO}_{2}$ [2]. It is estimated that 2000 - 4000 deaths could be avoided each year in Britain if the oxygen flow rate was more appropriate [1]. The accuracy of oxygen flow delivery system is therefore important. Oxygen supply is mostly controlled by rotameters (Thorpe Tube - Oxygen Flowmeter $=$ TT). The flow rates commonly delivered by these devices range from 0 to $15 \mathrm{l} / \mathrm{min}$, but other ranges are available (from $0-1.5 \mathrm{l} / \mathrm{min}$ to 0 - 70 l/min). Several types of TT exist based on different physical approaches: whether pressure is compensated or not, or pre-calibrated orifices or electromagnetic valves. These devices are simple but fragile. Their operation becomes inaccurate when exposed to static electricity or a magnetic field, secondary to a mechanical shock or a lack of verticality, but also with changes in atmospheric pressure or room temperature (depending on the model).

Davidson et al. [8] emphasize in their study that when ICU patients are being transferred to other wards, the patient's $\mathrm{SpO}_{2}$ was sometimes reduced while the $\mathrm{O}_{2}$ flow was not changed. According to these authors, the TT imprecision was a common cause of this altered $\mathrm{SpO}_{2}$. In Europe, the accuracy of flow measurement devices for connection to the wall outlet distribution systems of medical gases is governed by the ISO 15002 standards. Following this standard, the oxygen flow rate should not deviate from the nominal value by more than $0.5 \mathrm{l} / \mathrm{min}$ when the flow rate is below $5 \mathrm{l} / \mathrm{min}$, and by more than $10 \%$ above this threshold. The conditions in which the flow rate has to be evaluated are well standardized: temperature of $23^{\circ} \mathrm{C}\left( \pm 2^{\circ} \mathrm{C}\right)$ and atmospheric pressure of $1013 \mathrm{hPa}$. In North America, the requirement standards set by the CGA (Compressed Gas Association) are applied. These standards specify an allowable error of $10 \%$ around the nominal value. Few studies have attempted to assess the accuracy of TT in actual conditions of use. A previous study showed that the inaccuracy of TT varies from $10 \%$ to $40 \%$ of the desired value [9]. Therefore, the aim of our study was to evaluate the accuracy of wall-mounted oxygen flowmeter in actual conditions of use.

\section{Material and Methods}

This field study was conducted in 8 hospitals (number of beds $>250$ ). Thorpe Tube oxygen flowmeters (TT) (range: 0 to $15 \mathrm{l} / \mathrm{min}$ ) were studied in units for adults where oxygen is frequently delivered (intensive care, emergency unit, respiratory unit, cardiology, surgery) [1]. The evaluated TT was those used routinely in these services and allocated to the next patient requiring oxygen therapy. Firstly, the pressure in the local pipeline was checked. The TT was then plugged into the wall outlet of an unoccupied room and positioned vertically as a nurse might have done. Different gas flow rates were evaluated ( 2 to $15 \mathrm{l} / \mathrm{min}$ ) in a random order. The flow rate was set by aligning the center of the float ball with the indicator line of the suitable flow rate (nominal value) [10]. Each flow was measured twice and averaged for each TT. All settings and measurements were made by the same person. Particular attention was given to avoid parallax errors. Oxygen flows were measured using a calibrated thermal mass flowmeter (Red Y Compact ${ }^{\mathrm{TM}}$ GCM-0 to 20 l/min-VÖGTLIN Instrument—Switzerland, accuracy $1 \%$ of full scale, or $\pm 0.2 \mathrm{l} / \mathrm{min}$; digital display). This device is highly accurate and has the advantage of providing a measurement which is independent of the temperature and atmospheric pressure. Flow measurement is based on heat transfer between thermistors. This heat transfer depends on the mass of gas moving between these elements. When the device is crossed by a flow, the heated upstream thermistor cools and the downstream thermistor heats. The difference in heat gives information about the molecule amount moving through the system. Volume and flow rate are then calculated using this difference and transit time. The oxygen flow was measured after stabilization of the reading for 5 seconds. Different types of TT were encountered during our evaluations. They were classified into two groups according to whether they were pressure compensated (PCTT: Timeter $^{\mathrm{TM}}$, Caudalimeter ${ }^{\mathrm{TM}}$, RTM33 ${ }^{\mathrm{TM}}$, RTM2 ${ }^{\mathrm{TM}}$, Taema ${ }^{\mathrm{TM}}$ ) or not (NPCTT: Non-Pressure Compensated Thorpe Tube). 


\section{Statistical Analysis}

The flow values obtained were expressed in percent of the nominal value (\% NV). For each flow, the minimum, maximum, percentiles 25, 50 and 75, range and inter-quartile range (IQR) were calculated for the whole group and for subgroups based on the device pressure compensation. IQR was the difference between the 25th and 75th percentiles. The range was the difference between the maximum and minimum values. Error on the flow is the difference between the actual flow rate and the nominal flow rate in percentage. Mean values are expressed with their standard deviation. Flow rates from 2 to 5,6 to 10 and 11 to $15 \mathrm{l} / \mathrm{min}$ were considered respectively as low, medium and high flow rates.

The data were then compared using ANOVA on ranks test for repeated measures followed by Dunnett's test when a statistically significant difference was detected.

\section{Results}

476 oxygen flowmeters were analyzed in 8 hospitals (3 in France, 5 in Belgium) leading to a total of 13,328 measurements and 12 different brands of TT were encountered (Table 1). In both France and Belgium, the pressure compensated TT represented the majority of rotameters ( $70 \%$ and $66 \%$, respectively).

On average, the delivered flow rate corresponded to the nominal value (NV) with a median value ranging from $94 \%$ to $100 \%$ NV depending on the flow rate considered. However, data were widely dispersed around the nominal value with a lowest value of $48 \% \mathrm{NV}$ and a maximum value of $185 \% \mathrm{NV}$ leading to ranges of up to more than $100 \%$ NV. Data are reported separately for PCTT and NPCTT subgroups on Figure 1 and Table 2. In absolute terms, the dispersion of flow rate around the median value increased from $2.75 \mathrm{l} / \mathrm{min}$ for a required flow rate of $2 \mathrm{l} / \mathrm{min}$ to $11.2 \mathrm{l} / \mathrm{min}$ when the flow rate was set at $15 \mathrm{l} / \mathrm{min}$. In percentage terms, the range was particularly wide at low flow rate ( 2 to $4 \mathrm{l} / \mathrm{min}$ ) either by underestimating or overestimating the true flow rate. This dispersion at low flow rate (a range of $48 \%-185 \% \mathrm{NV}$ at $2 \mathrm{l} / \mathrm{min}$ ) was significantly wider than those observed for the other flow rates. These observations were not, in fact, exceptions. Indeed, when we considered interquartile values, the same wide dispersion was observed ( $30 \% \mathrm{VN}$ for $2 \mathrm{l} / \mathrm{min}$ to $15 \% \mathrm{VN}$ for $15 \mathrm{l} / \mathrm{min}$ ). This implied that half the devices were outside this range and resulted in a mean error on the flow of $18 \% \pm 5 \% \mathrm{NV}$. Error on the flow was present at low, medium and high flow rates. From one flow rate to the other, $31 \% \pm 9 \%$ of the devices were out of tolerable range when the ISO 15002 norm was considered. The figures were better at low flow rate because of an invariable $0.5 \mathrm{l} / \mathrm{min}$ tolerance below $5 \mathrm{l} / \mathrm{min}$ (Table 3). This constant tolerance at low flow rate is

\section{Table 1. Brand distribution.}

\begin{tabular}{|c|c|c|c|c|c|c|c|c|c|}
\hline \multirow{2}{*}{ Brands } & \multicolumn{3}{|c|}{ France } & \multicolumn{5}{|c|}{ Belgium } & \multirow[t]{2}{*}{ Total } \\
\hline & Site 1 & Site 2 & Site 3 & Site 1 & Site 2 & Site 3 & Site 4 & Site 5 & \\
\hline Air liquide ${ }^{\mathrm{TM}}$ & 3 & & 1 & 3 & & & & & 7 \\
\hline Caudalimeter ${ }^{\mathrm{TM}}$ & & & & & & & & 47 & 47 \\
\hline DKD médical ${ }^{\mathrm{TM}}$ & & 7 & & & & & & & 7 \\
\hline Drager ${ }^{\mathrm{TM}}$ & & & & & & & 4 & & 4 \\
\hline Heyer $^{\mathrm{TM}}$ & & & & & & & 10 & & 10 \\
\hline Puritan bennet ${ }^{\mathrm{TM}}$ & & & & 12 & & & & & 12 \\
\hline Rtm $1^{\mathrm{TM}}$ & 9 & 10 & 13 & & 16 & 12 & 26 & 51 & 32 \\
\hline $\mathrm{Rtm} 2^{\mathrm{TM}}$ & 11 & 6 & 9 & & 28 & 44 & & 10 & 108 \\
\hline Rtm3 $3^{\mathrm{TM}}$ & 5 & 11 & & 4 & 11 & 35 & & 9 & 75 \\
\hline Timeter $^{\mathrm{TM}}$ & & & & & & & 26 & & 26 \\
\hline Taema $^{\mathrm{TM}}$ & 15 & 27 & 1 & & & & & & 43 \\
\hline Total & 43 & 61 & 24 & 19 & 55 & 91 & 66 & 117 & 476 \\
\hline
\end{tabular}




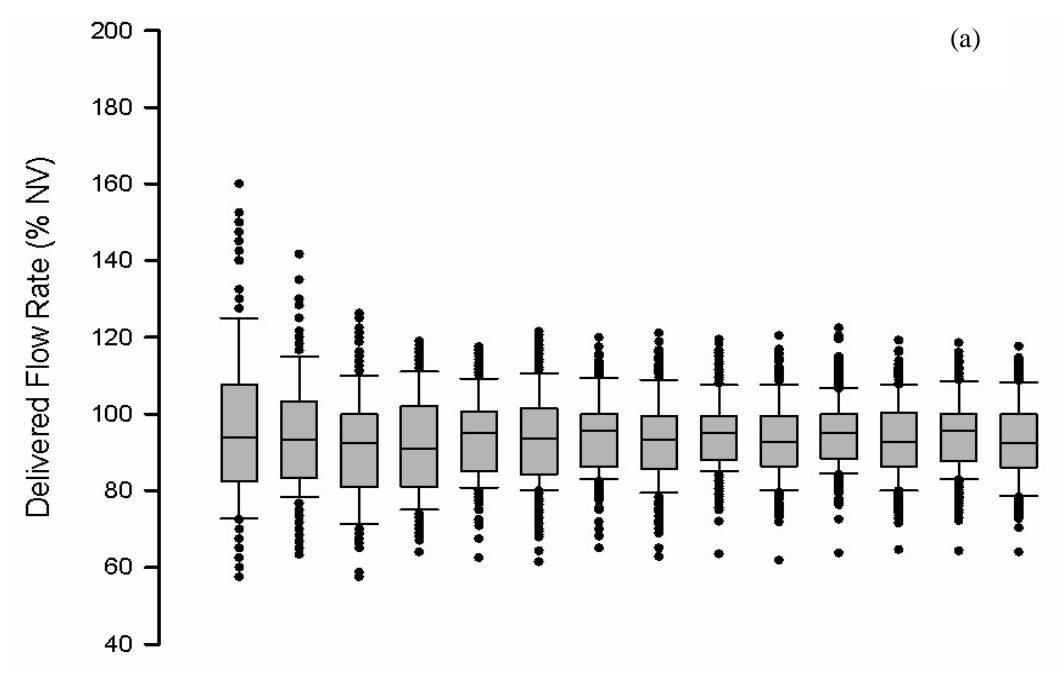

(b)

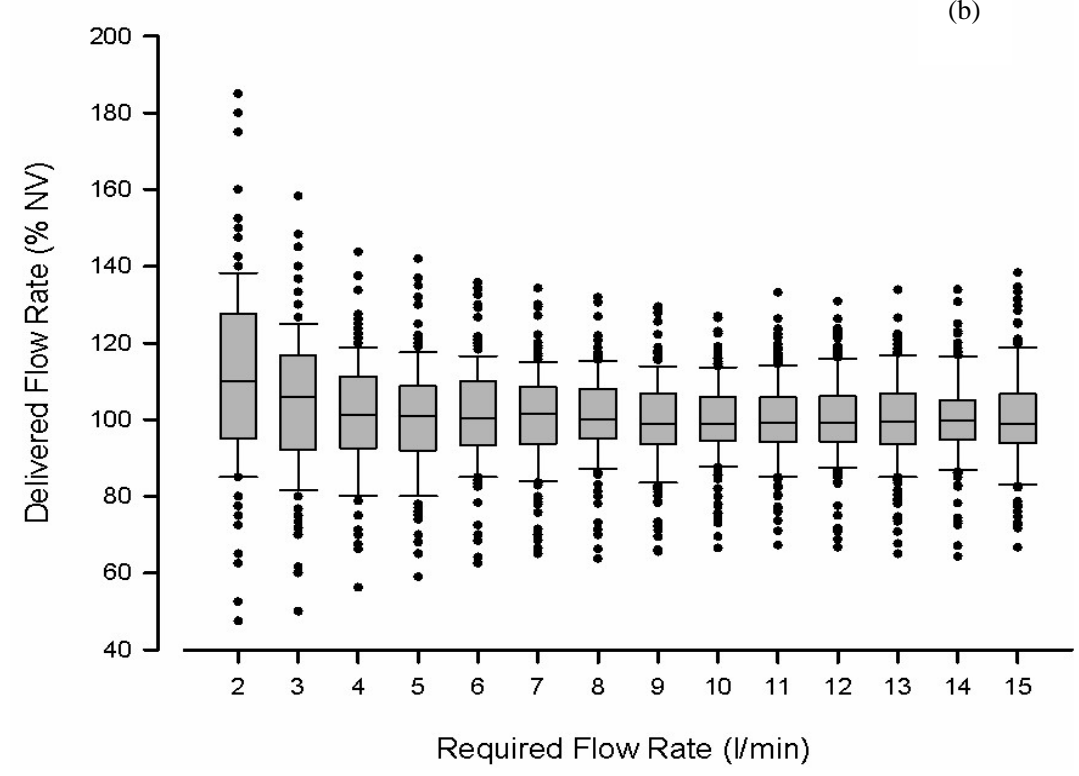

Figure 1. Validity of the delivered flow rate. Delivered flow rates are expressed in percentage of nominal flow rate $(\% \mathrm{NV})$. Value obtained in 320 compensated Thorpetube (Panel A) and 156 non-compensated Thorpe tube (Panel B) for required flow rate from 2 to $15 \mathrm{l} / \mathrm{min}$. Box illustrates first, second and third quartiles; whiskers correspond to percentiles 5 and 95; dots correspond to outliers. Median values (accuracy) are within tolerable range $( \pm 10 \% \mathrm{VN})$ but the wide dispersion around medians reflects a poor precision.

not present in the CGA guidelines and the difference disappeared when this norm was used. On average, $35 \% \pm$ $7 \%$ of the flowmeters were then considered as inaccurate. When PCTT were compared to NPCTT, no statistically-significant difference was observed in the median or range values. An intolerable inaccuracy was however more frequent in the NPCTT group.

The percentage of device outside the acceptable range following the ISO 15002 and the CGA are shown in Table 3. At low flow rates, the PCTT performed better than the NPCTT and the inverse was true at high flow rates $(\mathrm{p}<0.05)$.

\section{Discussion}

When the flowmeter leaves the factory, its accuracy in standard conditions is guaranteed by the manufacturer. 
Table 2. Distribution of delivered flow rate (expressed as a percentage of the required flow rate).

\begin{tabular}{|c|c|c|c|c|c|c|c|c|c|c|c|c|c|c|}
\hline \multirow{3}{*}{ (\% N.V.) } & \multicolumn{14}{|c|}{ Pressure compensated Thorpe tube } \\
\hline & \multicolumn{14}{|c|}{ Oxygen flow rate nominal value (l/min) } \\
\hline & 2 & 3 & 4 & 5 & 6 & 7 & 8 & 9 & 10 & 11 & 12 & 13 & 14 & 15 \\
\hline Maximum & $160 \%$ & $142 \%$ & $126 \%$ & $119 \%$ & $118 \%$ & $121 \%$ & $120 \%$ & $121 \%$ & $120 \%$ & $121 \%$ & $123 \%$ & $119 \%$ & $119 \%$ & $118 \%$ \\
\hline Percentile 75 & $108 \%$ & $103 \%$ & $100 \%$ & $102 \%$ & $101 \%$ & $101 \%$ & $100 \%$ & $99 \%$ & $99 \%$ & $100 \%$ & $100 \%$ & $100 \%$ & $100 \%$ & $100 \%$ \\
\hline Median & $94 \%$ & $93 \%$ & $93 \%$ & $91 \%$ & $95 \%$ & $94 \%$ & $96 \%$ & $93 \%$ & $95 \%$ & $93 \%$ & $95 \%$ & $93 \%$ & $96 \%$ & $92 \%$ \\
\hline Percentile 25 & $83 \%$ & $83 \%$ & $81 \%$ & $81 \%$ & $85 \%$ & $84 \%$ & $86 \%$ & $86 \%$ & $88 \%$ & $86 \%$ & $88 \%$ & $86 \%$ & $88 \%$ & $86 \%$ \\
\hline Minimum & $58 \%$ & $63 \%$ & $58 \%$ & $64 \%$ & $63 \%$ & $61 \%$ & $65 \%$ & $63 \%$ & $64 \%$ & $62 \%$ & $64 \%$ & $65 \%$ & $64 \%$ & $64 \%$ \\
\hline IQR & $25 \%$ & $20 \%$ & $19 \%$ & $21 \%$ & $16 \%$ & $17 \%$ & $14 \%$ & $14 \%$ & $11 \%$ & $13 \%$ & $12 \%$ & $14 \%$ & $12 \%$ & $14 \%$ \\
\hline \multirow[t]{3}{*}{ Range } & $103 \%$ & $78 \%$ & $69 \%$ & $55 \%$ & $55 \%$ & $60 \%$ & $55 \%$ & $58 \%$ & $56 \%$ & $59 \%$ & $59 \%$ & $55 \%$ & $54 \%$ & $54 \%$ \\
\hline & \multicolumn{14}{|c|}{ Non-pressure compensated Thorpe tube } \\
\hline & 2 & 3 & 4 & 5 & 6 & 7 & 8 & 9 & 10 & 11 & 12 & 13 & 14 & 15 \\
\hline Maximum & $185 \%$ & $158 \%$ & $144 \%$ & $142 \%$ & $136 \%$ & $134 \%$ & $132 \%$ & $129 \%$ & $127 \%$ & $133 \%$ & $131 \%$ & $134 \%$ & $134 \%$ & $138 \%$ \\
\hline Percentile 75 & $128 \%$ & $117 \%$ & $111 \%$ & $109 \%$ & $110 \%$ & $109 \%$ & $108 \%$ & $107 \%$ & $106 \%$ & $106 \%$ & $106 \%$ & $107 \%$ & $105 \%$ & $107 \%$ \\
\hline Median & $110 \%$ & $106 \%$ & $101 \%$ & $101 \%$ & $100 \%$ & $101 \%$ & $100 \%$ & $99 \%$ & $99 \%$ & $99 \%$ & $99 \%$ & $99 \%$ & $100 \%$ & $99 \%$ \\
\hline Percentile 25 & $95 \%$ & $92 \%$ & $93 \%$ & $92 \%$ & $93 \%$ & $94 \%$ & $95 \%$ & $94 \%$ & $95 \%$ & $94 \%$ & $94 \%$ & $94 \%$ & $95 \%$ & $94 \%$ \\
\hline Minimum & $48 \%$ & $50 \%$ & $56 \%$ & $59 \%$ & $63 \%$ & $65 \%$ & $64 \%$ & $66 \%$ & $67 \%$ & $67 \%$ & $67 \%$ & $65 \%$ & $64 \%$ & $67 \%$ \\
\hline IQR & $33 \%$ & $25 \%$ & $19 \%$ & $17 \%$ & $17 \%$ & $15 \%$ & $13 \%$ & $13 \%$ & $11 \%$ & $12 \%$ & $12 \%$ & $13 \%$ & $10 \%$ & $13 \%$ \\
\hline Range & $138 \%$ & $108 \%$ & $88 \%$ & $83 \%$ & $73 \%$ & $69 \%$ & $68 \%$ & $64 \%$ & $61 \%$ & $66 \%$ & $64 \%$ & $69 \%$ & $70 \%$ & $72 \%$ \\
\hline
\end{tabular}

Table 3. Proportion of Thorpe tube out of standard limits.

\begin{tabular}{|c|c|c|c|c|c|c|c|c|c|c|c|c|c|c|c|}
\hline \multirow{2}{*}{ Standard } & \multirow{2}{*}{ TT Type } & \multicolumn{14}{|c|}{ Oxygen flow rate (1/min) } \\
\hline & & 2 & 3 & 4 & 5 & 6 & 7 & 8 & 9 & 10 & 11 & 12 & 13 & 14 & 15 \\
\hline \multirow{2}{*}{ ISO 15002} & PCTT & $8 \%$ & $15 \%$ & $37 \%$ & $45 \%$ & $38 \%$ & $43 \%$ & $37 \%$ & $43 \%$ & $30 \%$ & $41 \%$ & $32 \%$ & $42 \%$ & $36 \%$ & $40 \%$ \\
\hline & NPCTT & $17 \%$ & $23 \%$ & $25 \%$ & $31 \%$ & $27 \%$ & $29 \%$ & $25 \%$ & $28 \%$ & $24 \%$ & $31 \%$ & $24 \%$ & $32 \%$ & $26 \%$ & $31 \%$ \\
\hline \multirow{2}{*}{ CGA } & PCTT & $36 \%$ & $38 \%$ & $45 \%$ & $45 \%$ & $38 \%$ & $43 \%$ & $37 \%$ & $43 \%$ & $30 \%$ & $41 \%$ & $32 \%$ & $42 \%$ & $36 \%$ & $40 \%$ \\
\hline & NPCTT & $48 \%$ & $39 \%$ & $31 \%$ & $31 \%$ & $27 \%$ & $29 \%$ & $25 \%$ & $28 \%$ & $24 \%$ & $31 \%$ & $24 \%$ & $32 \%$ & $26 \%$ & $31 \%$ \\
\hline
\end{tabular}

With time and usage, its precision can become altered and the accuracy of the flow delivered in a hospital environment can differ from its original value. This study is the first large multi-centric study evaluating the accuracy of wall-mounted oxygen flowmeters in common conditions of use. Evaluation of malpractice was not the objective of the present study and the method used to adjust flow rate was strictly in accordance with the manufacturer's instructions. Our analysis shows that, on average, delivered oxygen flows are close to desired oxygen flow (nominal value). At first sight, this appears satisfactory. However, the oxygen flow rate dispersion around the median value is very large and the flow rate actually delivered can therefore differ hugely from the one desired (from half to nearly twice the suitable flow rate). These results obtained in a European setting confirm the results from a Brazilian study with South American-brand oxygen flowmeters [8]. Based on international standards, a significant error in the delivered flow is so frequently observed that nearly $33 \% \pm 8 \%$ of oxygen flowmeters should be removed from use. The inaccuracy of oxygen flowmeters might raise concerns any time the device has to be changed. This is the case, for instance, when a patient has to move from one hospital department to another, or when a flow rate determined at hospital has to be applied at home. The absence of reproducibility 
between devices can lead to a variation in the oxygen flow actually delivered and to the over- or under-oxygenation of patients. Long-term oxygen therapy at home has shown its ability to correct hemodynamics in hypoxic COPD patients and to improve their chances of survival [11]. However, it has also been shown that an inadequate oxygen supply was ineffective in increasing the life expectancy in these patients [11].

Either in acute hospital and chronic at-home oxygen therapy, this under-oxygenation problem can easily be addressed by checking the transcutaneous saturation each time a new device is used and by adapting the required flow rate to the new situation. At the opposite end, over-oxygenation is more problematic because some COPD patients and patients with obesity hypoventilation syndrome develop a hypercapnic decompensation with respiratory acidosis when an excessive oxygen flow is delivered and this even when transcutaneous saturation initially reaches the target value. It is therefore important to have accurate and reliable devices available, especially when blood gas analysis is not directly accessible.

Finally, inappropriate flow can cause logistical problems. This supply problem can be critical during transport outside the hospital or when oxygen therapy is used to increase mobility and ambulation time.

In conclusion, these results confirm the limited accuracy of wall-mounted oxygen flowmeters when studied in an actual hospital setting. This could lead to inappropriate oxygenation particularly at low flow rate. An adaptation of the required flow rate is therefore mandatory after each change of device. Furthermore, a periodic assessment of flowmeters should be recommended in order to discard the more deviant devices. As in pressure compensated Thorpe Tube the control valve is located downstream of the reading tube, the flow is operated at a pressure equal to that of the pipeline. These apparatuses are therefore less sensitive to environmental conditions. At low flow rate, we observed a better accuracy for these devices.

\section{References}

[1] O’Driscoll, B.R. and Howard, L.S. (2011) Audit Update: British Thoracic Society Emergency Oxygen Audits. Thorax, 66, 734-735. http://dx.doi.org/10.1136/thoraxjnl-2011-200078

[2] O’Driscoll, B.R., Howard, L.S. and Davidson, A.G. (2008) British Thoracic Society Guideline for Emergency Oxygen Use in Adult Patients. Thorax, 63, vi1-vi68. http://dx.doi.org/10.1136/thx.2008.102947

[3] Ingrassia, T.S., Ryu, J.H., Trastek, V.F. and Rosenow, E.C. (1991) Oxygen-Exacerbated Bleomycin Pulmonary Toxicity. Mayo Clinic Procedure, 66, 173-178. http://dx.doi.org/10.1016/S0025-6196(12)60489-3

[4] Pratt, I.S., Keeling, P.L. and Smith, L.L. (1980) The Effect of High Concentrations of Oxygen on Paraquat and Diquat Toxicity in Rats. Archives of Toxicology Supplement, 4, 415-418. http://dx.doi.org/10.1007/978-3-642-67729-8 95

[5] Bedrossian, R. (1953) Retinopathy of Prematurity (Retrolental Fibroplasia) and Its Relationship to Oxygen. AMA Archives of Ophthalmology, 50, 266-267.

[6] Hedenstierna, G. and Edmark, L. (2010) Mechanisms of Atelectasis in the Perioperative Period. Best Practice \& Research Clinical Anaesthesiology, 24, 157-169. http://dx.doi.org/10.1016/j.bpa.2009.12.002

[7] Tachtsidis, I., Tisdall, M.M., Leung, T.S., Pritchard, C., Cooper, C.E., Smith, M. and Elwel, C.E. (2009) Relationship between Brain Tissue Haemodynamics, Oxygenation and Metabolism in the Healthy Human Adultbrain during Hyperoxia and Hypercapnea. Advances in Experimental Medicine and Biology, 645, 315-320. http://dx.doi.org/10.1007/978-0-387-85998-9 47

[8] Davidson, J., Gazzeta, C., Torres, L.C., Jardim, J.R. and Nascimento, O.A. (2012) Precision and Accuracy of Oxygen Flowmeters Used at Hospital Settings. Respiratory Care, 57, 1071-1075. http://dx.doi.org/10.4187/respcare.01230

[9] Waaben, J., Brinkløv, M.M. and Stokke, D.B. (1980) Accuracy of New Gas Flowmeters. British Journal of Anaesthesia, 52, 97-100. http://dx.doi.org/10.1093/bja/52.1.97

[10] Cairo, J.M. (1999) Administering Medical Gases: Regulators, Flowmeters, and Controlling Devices. In: Cairo, J.M., and Pilbeam, S.P., Eds., Respiratory Care Equipment, 6th Edition. Mosby’s, Inc., New York, 66.

[11] Nocturnal Oxygen Therapy Trial Group (1980) Continuous or Nocturnal Oxygen Therapy in Hypoxemic Chronic Obstructive Lung Disease: A Clinical Trial. Annals of Internal Medicine, 93, 391-398. http://dx.doi.org/10.7326/0003-4819-93-3-391 
Scientific Research Publishing (SCIRP) is one of the largest Open Access journal publishers. It is currently publishing more than 200 open access, online, peer-reviewed journals covering a wide range of academic disciplines. SCIRP serves the worldwide academic communities and contributes to the progress and application of science with its publication.

Other selected journals from SCIRP are listed as below. Submit your manuscript to us via either submit@scirp.org or Online Submission Portal.
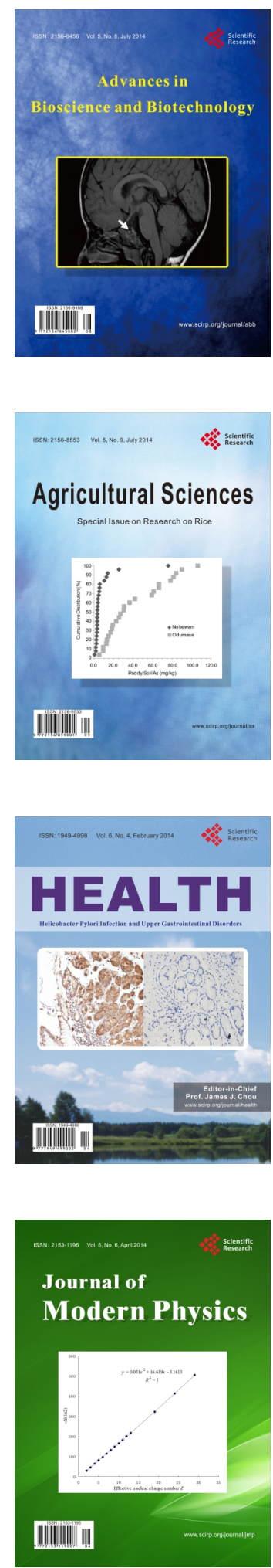
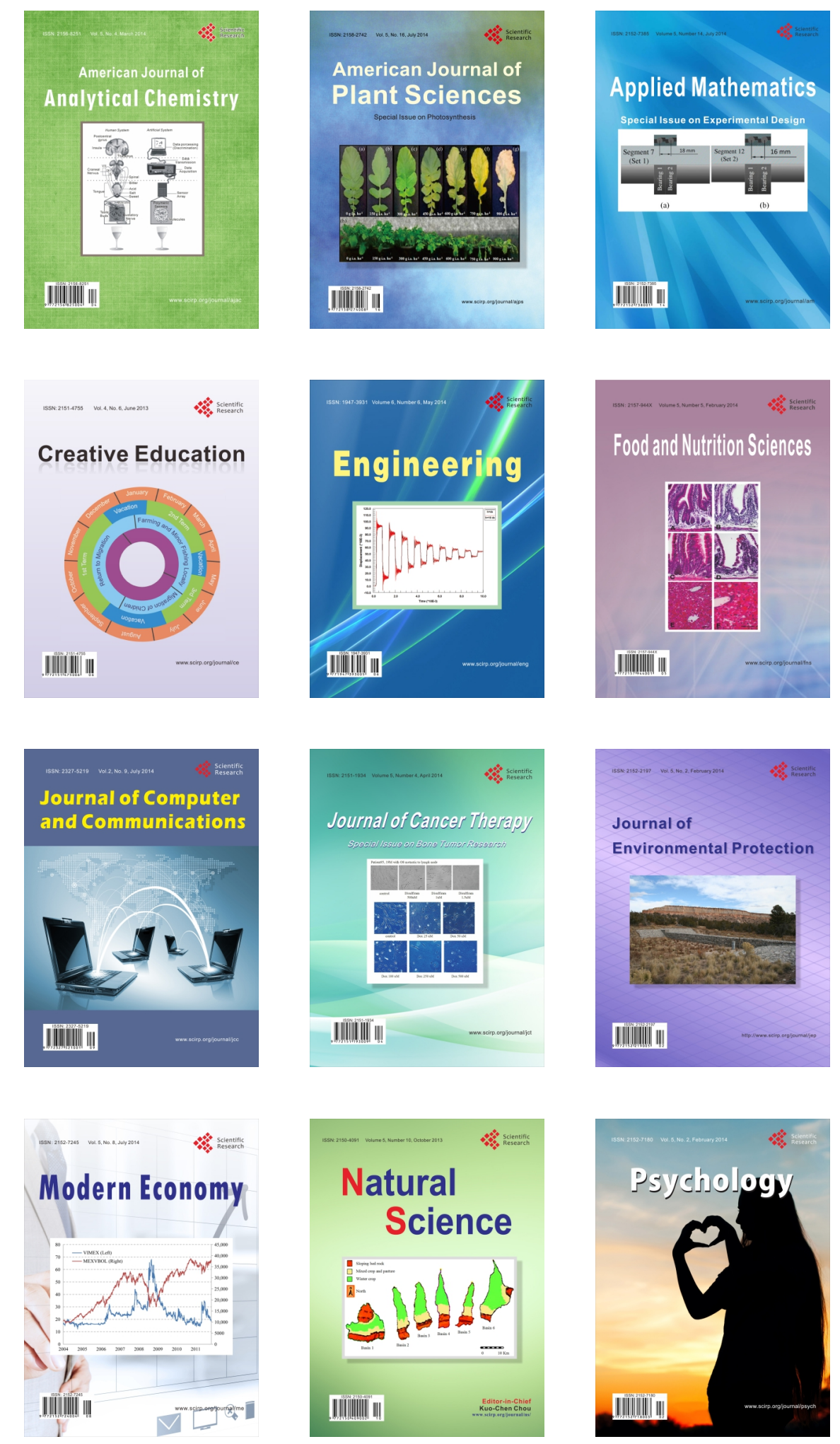